\title{
Generalized olfactory detection of floral volatiles in the highly specialized Greya-Lithophragma nursery pollination system
}

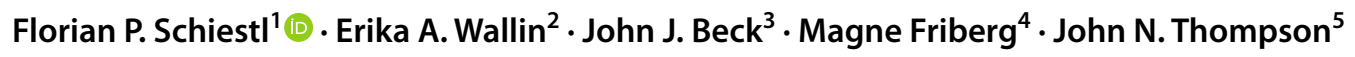

Received: 20 October 2020 / Accepted: 2 February 2021 / Published online: 5 March 2021

(c) The Author(s) 2021

\begin{abstract}
Volatiles are of key importance for host-plant recognition in insects. In the pollination system of Lithophragma flowers and Greya moths, moths are highly specialized on Lithophragma, in which they oviposit and thereby pollinate the flowers. Floral volatiles in Lithophragma are highly variable between species and populations, and moths prefer to oviposit into Lithophragma flowers from populations of the local host species. Here we used gas chromatography coupled with electroantennographic detection (GC-EAD) to test whether Greya moths detect specific key volatiles or respond broadly to many volatiles of Lithophragma flowers. We also addressed whether olfactory detection in Greya moths varies across populations, consistent with a co-evolutionary scenario. We analyzed flower volatile samples from three different species and five populations of Lithophragma occurring across a $1400 \mathrm{~km}$ range in the Western USA, and their sympatric female Greya politella moths. We showed that Greya politella detect a broad range of Lithophragma volatiles, with a total of 23 compounds being EAD active. We chemically identified 15 of these, including the chiral 6,10,14-trimethylpentadecan-2-one (hexahydrofarnesyl acetone), which was not previously detected in Lithophragma. All investigated Lithophragma species produced the (6R, $10 R$ )-enantiomer of this compound. We showed that Greya moths detected not only volatiles of their local Lithophragma plants, but also those from allopatric populations/species that they not encounter in local populations. In conclusion, the generalized detection of volatiles and a lack of co-divergence between volatiles and olfactory detection may be of selective advantage for moths in tracking hosts with rapidly evolving, chemically diverse floral volatiles.
\end{abstract}

Keywords Coevolution $\cdot$ Floral scent $\cdot$ Pollination $\cdot$ GC-EAD $\cdot$ Olfaction $\cdot$ Olfactory receptors

\section{Introduction}

In specialized, interspecific interactions with reciprocal fitness consequences, coevolution between the interacting partners is often the consequence (Thompson 2005). A key model system for the investigation of coevolution in plant-insect associations has been the woodland star flower (Lithophragma) and Greya moths nursery pollination system (Thompson 2005; Thompson and Cunningham 2002; Thompson et al. 2017). In this system, Greya moths pollinate the flowers while ovipositing into them through the corolla or while nectaring, and Greya larvae feed on developing seeds. The Greya-Lithophragma pollination system is an open nursery system in which moths are highly specific to their local Lithophragma host species and are often the major pollinators of their hosts. The term "open nursery pollination system" refers to the fact that co-pollinators, that do not lead to destruction of seeds, also contribute to pollination in varying degrees among Lithophragma populations 
and species (Thompson and Cunningham 2002; Thompson et al. 2017). Thus, whereas nursery pollination systems without co-pollinators are generally mutualistic, this system varies between mutualism and antagonism on a geographical mosaic scale, depending on the number of Greya species interacting with one Lithophragma species and the number of generalized co-pollinators present (Thompson and Cunningham 2002).

Like many insects (Bruce and Pickett 2011), Greya moths are thought to use plant odor as a cue of primary importance for host plant identification (Friberg et al. 2014). For olfaction, insects employ sets of highly sensitive, and often specifically tuned olfactory neurons (de Fouchier et al. 2017). To identify host plants, many insects use blends of common volatiles, but some use only specific compounds that serve as identification cue of their food plants (Bengtsson et al. 2011; de Fouchier et al. 2017; Schiestl 2015). In plant-pollinator interactions, examples of such olfactory "private channels" are spiroacetals emitted by bellflowers (Milet-Pinheiro et al. 2013), 1,4-benzoquinone produced by Echium flowers (Burger et al. 2012), 4-methyl-5-vinylthiazol in Cyclocephala-pollinated Araceae inflorescences (Maia et al. 2012), and diacetin from plants with oil as floral reward (Schaeffler et al. 2015). An additional aspect of such specificity is the use of specific enantiomers of chiral molecules. Several studies have shown that insects may respond only to specific enantiomers of a given volatile (Bohman et al. 2018; Borg-Karlson et al. 2003; Eltz et al. 2010), or to specific ratios of enantiomers (Chen and Song 2008), pointing out the need to better understand the enantiomeric composition of semiochemcials. Whereas geographic variation in volatile blends has commonly been documented, potential variation in enantiomeric composition of chiral molecules is very little understood but may contribute to population-specificity in chemical signals (Raguso 2016).

Specialization of insects to particular host plants may involve evolutionary change in the sensitivity of olfactory neurons towards different ligands. In principle, change in host plants or food sources should select for changes in the olfactory system to allow optimal detection of food. This may not always be the case, for example, if common volatiles are shared by different food sources (Bengtsson et al. 2011). Phylogenetic studies have indeed shown that related olfactory neurons often detect similar compound classes across large taxonomic groups of insects, suggesting conservative evolution of receptor sensitivity in these insects (de Bruyne et al. 2010; de Fouchier et al. 2017; Jones et al. 2005). Nevertheless, some examples of apparent rapid change in odor sensitivity are also known (Blazyte-Cereskiene et al. 2019; de Bruyne et al. 2010; Metcalf et al. 1979; Schaeffler et al. 2015).

A fascinating, yet almost unexplored question is whether and how rapidly receptor sensitivity may co-evolve with plant volatile emission (Schiestl and Dötterl 2012). Floral scent in Lithophragma is chemically highly diverse, both among populations and species (Friberg et al. 2013, 2019), indicating rapid evolutionary divergence in this key floral signal (Ramos and Schiestl 2020). Such pattern of high variability has been found in other nursery pollination systems, too (Dötterl et al. 2005; Suinyuy et al. 2015; Waelti et al. 2008), but contrasts to the highly conserved odor bouquets found in yucca flowers (Svensson et al. 2005, 2006, 2011). Yucca flowers form a highly specialized nursery pollination association with yucca moths, which are closely related to Greya moths (Thompson 2010).

Given the specificity and tight dependence of Greya moths on Lithophragma host plants, adaptation to the region-specific floral volatile bouquets could be expected. Indeed, Friberg et al. (2014) found evidence that moths from three of the locations used here (TUR, SED, MBL), by using floral volatiles, prefer sympatric flowers for oviposition and often ignore flowers from allopatric species. In no-choice oviposition tests, more moths oviposited into sympatric host species, but a few also oviposited into allopatric ones. This result suggests differentiation in the moths' olfactory perception, so that allopatric flowers are often not chosen, even though they would likely be suitable oviposition substrates, as all species within the $L$. parviflorum and $L$. campanulatum clades are suitable hosts within some part of the range of G. politella (Thompson et al. 2017). Hence, preference of G. politella for any particular Lithophragma is likely due to local specialization rather than to inherent major differences among Lithophragma species as suitable hosts.

Here we present data of the first study of electrophysiological detection of Lithophragma floral volatiles by Greya moths. This approach was chosen to determine whether Greya moths detect specific key compounds or respond broadly to many different floral volatiles. We also addressed the question of geographic variation in responses, namely whether Greya moths do/do not respond to floral volatiles of allopatric Lithophragma plants (i.e. those that they normally not encounter). A lack of (or notably reduced) response to allopatric volatiles would indicate co-divergence of olfactory sensitivity and volatile bouquets. Finally, we found a chiral volatile not-yet detected in Lithophragma, 6, 10, 14-trimethylpentadecan-2-one, which was highly EAD-active in Greya moths. This compound acts as a phagostimulant in the fall armyworm, Spodoptera frugiperda (Mohamed et al. 1992), has been reported as sex pheromone in some Lepidoptera (Nieberding et al. 2008) and is known to have enantiomerspecific behavioral activity in euglossine bees (Eltz et al. 2010). Hence, we characterized the enantiomeric composition of this compound as well as geographic variation thereof. If true, this may provide a previously undetected population- or species-specific chemical profile of flowers. 
We used floral volatile samples from five populations, which included three closely related species of Lithophragma (Kuzoff et al. 1999), and their sympatric moths (see methods section and Table 1), occurring in contrasting habitats near the northern and southern edges of the geographic distribution of these interactions. For the assessment of electrophysiological activity and differences in activity between populations, we used gas chromatography coupled to electroantennographic detection (GC-EAD). This method broadly screens volatile samples for electrophysiologically active compounds, which is desirable in systems where olfactory detection of volatiles has not yet been investigated, in order not to miss any potential key compounds produced in small amounts. This method, however, may have a high detection threshold (depending on the sensitivity, specialization, abundance of antennal receptors, and background noise), and does not allow for a fine-tuned quantitative assessment of receptor sensitivity. Other, more quantitative/ sensitive methods such as electroantennography (EAG) or single sensillum recording require previous knowledge of active compounds (Schiestl and Marion-Poll 2002) and were thus not applied in this study. Therefore, our comparison of population-specific detection of volatiles by moths was done only on a qualitative basis (response/no response), without any quantitative comparison of intensities of responses.

\section{Methods and materials}

\section{Plants, insects}

Experiments were conducted in spring 2015 and 2016. Greya politella moths (Lepidoptera: Prodoxidae) are completely dependent on the Lithophragma (Saxifragaceae) host plants, whereas the dependence of Lithophragma on Greya as pollinators can be reduced, at least at some sites, when generalized co-pollinators are abundant (Thompson and Cunningham 2002). Greya moth males search for females by flying among host flowers. Adults mate on and take nectar from flowers, and females pollinate the host flowers during nectaring and oviposition. The larvae feed on a fraction of the seeds before spending the dry summer months in diapause near or in the root system. In spring, larvae continue to feed on the leaves and pupate in a rolled-up leaf.

Lithophragma volatiles and G. politella moths were collected from the following populations in California and Washington State, USA: Lithophragma cymbalaria (SED: Sedgwick, University of California, Sedgwick Reserve, California: $3442.871^{\prime} \mathrm{N}, 1202.999^{\prime} \mathrm{W}$ ), L. bolanderi (MBL: Marble Falls Trail, Kaweah River, California: $3631.198^{\prime} \mathrm{N}$, 118 48.024'W; WOO: Woody, California: 3543.176 'N, 118 47.907`W; KNG: King's River, California: 3651.536 'N, 119 $06.202^{\prime} \mathrm{W}$; no flower samples were available from $\mathrm{KNG}$, and no moths from WOO), and L. parviflorum (TUR: Turnbull National Wildlife Refuge, Washington State: $4724.185^{\prime} \mathrm{N}$, $\left.11734.103^{\prime} \mathrm{W}\right)$. The northern and southern edge populations were separated by approximately $1400 \mathrm{~km}$, and the southern edge populations were separated, west to east, by up to approximately $230 \mathrm{~km}$. The moth populations at these geographically extreme sites differed in the Lithophragma species they used as hosts. The Lithophragma species and populations differ dramatically, both quantitatively and qualitatively, in their floral scent bouquets (Friberg et al. 2013, 2014, 2017, 2019). Similarly, the G. politella moths from these locations are genetically diverged to an extent that they may be considered different cryptic species (Rich et al. 2008).

In 2015, only floral headspace samples were collected and analyzed; in 2016, headspace samples of SED, and flower extracts of all populations were collected/analyzed. Female moths were collected from the same populations by catching individuals sitting on flowers of each local Lithophragma species. Moths were kept in Eppendorf tubes with a hole punched in the lid, in a refrigerator at $4{ }^{\circ} \mathrm{C}$, where they survived for up to 10 days without feeding. Nevertheless, moths were usually used within $2-5$ days after capture for GC-EAD recordings.

\section{Headspace volatile collection}

We collected floral scent from whole inflorescences for gas chromatography-electroantennographic detection (GCEAD), using headspace collection with Porapak Q as adsorbent (Huber et al. 2005; Knauer and Schiestl 2015). Because GC-EAD requires highly concentrated samples in case of high detection thresholds, we included in each sample multiple, freshly cut inflorescences from multiple plants that collectively had up to 100 flowers. The inflorescences were enclosed in oven bags (Reynolds ${ }^{\circledR}$, Richmond, VA, USA), and a glass tube filled with $4 \mathrm{mg}$ of Porapak Q (Mesh size 80/100; Alltech Associates Inc., Deerfield, IL, USA) was inserted into the bag. The use of low amounts of adsorbent in a narrow tube allows for elution of collected volatiles with low volumes of solvent, thus avoiding the need to concentrate samples after collection. The Porapak was enclosed by a layer of quartz wool and glass beads $(0.3 \mathrm{~mm}$, Merck KGaA, Darmstadt, Germany) fused into the glass tube by heating on both sides. Before use, all Porapak tubes were cleaned with $400 \mu$ dichloromethane. The tubes were connected with a silicon tube to a Micro Air Sampler (PAS-500 Micro Air Sampler, Spectrex, Redwood City, CA, USA), which pulled air through the filter with a flow of $100 \mathrm{ml} \mathrm{min}^{-1}$ for 2-3 $\mathrm{h}$. As a control for ambient contaminants, we collected scent from an empty bag using the same collection parameters. After sampling, we eluted the trapped volatile compounds with $50 \mu \mathrm{l}$ of a hexane and acetone (9:1) mixture (for all 
solvents, HPLC grade was used). All samples were stored in $2 \mathrm{ml}$ glass vials at $-30{ }^{\circ} \mathrm{C}$ until analysis with GC-EAD and GC-MSD (GC-EAD; Schiestl and Marion-Poll 2002).

\section{Flower extract collection}

We collected low-volatile compounds from flowers, by rinsing up to 300 cut flowers from ca. 30 plants for $30 \mathrm{~s}$ in $1-5 \mathrm{ml}$ (depending on the number of flowers) solvent and then immediately removing them from the solvent. As solvent, we used a mixture of 9:1 hexane: acetone. The resulting crude extract was then either concentrated to $500 \mu \mathrm{l}$ volume under a stream of $\mathrm{N}_{2}$ and subsequently directly injected into the GC, or further purified using solid phase extraction (SPE) with $500 \mathrm{mg}$ silica columns (Supelco), following Hedenström et al. (2015). Approximately $100 \mu \mathrm{l}$ of concentrated extract was applied on the column bed and the solvent evaporated under a stream of $\mathrm{N}_{2}$. Elution of different compound fraction was then achieved with stepwise gradient elution with $0-10 \%$ ethyl acetate in pentane, in steps of $1 \%$ increase. Fraction 1 was pure pentane and fraction 11 was pentane with $10 \%$ ethyl acetate. $200 \mu \mathrm{l}$ solvent was used for each for elution; the solvent was slowly pulled through the silica bed with vacuum. Elution 1-3 (mostly alkanes), 4-8 (mostly ketones), and 9-11 (mostly alcohols) were pooled and concentrated over an $\mathrm{N}_{2}$ flow to ca $200 \mu$ l. The GC-EAD was then performed with the different fractions.

\section{Electrophysiology}

Gas chromatographic analysis with electroantennographic detection (GC-EAD; Schiestl and Marion-Poll 2002) of volatile samples was performed using a gas chromatograph (Agilent 6890 N, Agilent Technologies, Palo Alto, CA, USA) equipped with a heated outlet for electroantennographic recordings (Effluent Conditioning Assembly, Syntech, Hilversum, the Netherlands). Antennal responses of female Greya moths were measured via EAD. For EAD recordings, the tip of the excised antenna was abscised and the antenna was mounted on an antennal holder using electrode gel. The antennal holder was connected via a signal interface box (Syntech, Hilversum, The Netherlands) to a personal computer. $5 \mu \mathrm{l}$ of the samples were injected splitless $\left(250^{\circ} \mathrm{C}\right)$ at an oven temperature of $50^{\circ} \mathrm{C}(1 \mathrm{~min})$ into the GC followed by heating to $240{ }^{\circ} \mathrm{C}$ at a rate of $10^{\circ} \mathrm{C} \mathrm{min}^{-1}$. The GC was equipped with a DB-WAX (J\&W Scientific, Folsom, CA, USA) column ( $0.325 \mathrm{~mm}$ diameter, $0.25 \mu \mathrm{m}$ film thickness, $30 \mathrm{~m}$ length) and a flame ionization detector (FID). Helium was used as carrier gas at a flow of $2 \mathrm{ml} \mathrm{min}^{-1}$. A GC effluent splitter (Agilent G2855 Deans Switching System, Agilent Technologies, Palo Alto, CA, USA) was used to direct

Table 1 GC-EAD-active volatiles in Lithophragma headspace samples and synthetic blends

\begin{tabular}{|c|c|c|c|c|c|c|c|c|c|c|c|c|c|c|c|c|c|c|c|c|c|}
\hline $\begin{array}{l}\text { Lithophragma } \\
\text { species/region } \\
\text { (population) }\end{array}$ & $\begin{array}{l}\text { Greya } \\
\text { politella } \\
\text { pop. }\end{array}$ & 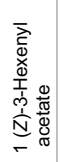 & $\underset{\sim}{\check{D}}$ & 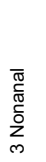 & 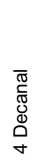 & 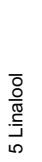 & $\begin{array}{l}N \\
5\end{array}$ & 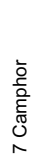 & 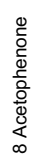 & $\begin{array}{l}m \\
\dot{5} \\
0\end{array}$ & 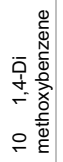 & 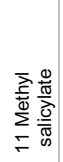 & 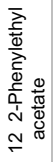 & 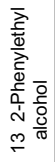 & $\begin{array}{l}\dot{\square} \\
\dot{a}\end{array}$ & 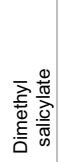 & 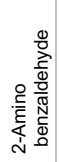 & 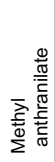 & 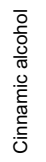 & $\sum_{i}^{0}$ & 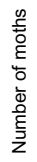 \\
\hline $\begin{array}{l}\text { L. cymbalaria } \\
\text { (SED) }\end{array}$ & SED & n.p. & n.p. & $\sqrt{ }$ & low & $\sqrt{ }$ & n.p. & n.p. & n.p. & n.p. & n.p. & $\sqrt{ }$ & n.p. & n.p. & n.p. & $\sqrt{ }$ & $\sqrt{ }$ & $\sqrt{ }$ & n.p. & n.p. & 4 \\
\hline $\begin{array}{l}\text { L. bolanderi } \\
\text { (MBL) }\end{array}$ & MBL & $\sqrt{ }$ & $\sqrt{ }$ & $\sqrt{ }$ & $\sqrt{ }$ & $\sqrt{ }$ & $\sqrt{ }$ & $\sqrt{ }$ & $\sqrt{ }$ & $\sqrt{ }$ & n.p. & $\sqrt{ }$ & $\sqrt{ }$ & $\sqrt{ }$ & $\sqrt{ }$ & n.p. & $\sqrt{ }$ & $\sqrt{ }$ & $\sqrt{ }$ & n.p. & 3 \\
\hline $\begin{array}{l}\text { L. bolanderi } \\
\text { (MBL) }\end{array}$ & KNG & $\sqrt{ }$ & $\sqrt{ }$ & $\sqrt{ }$ & $\sqrt{ }$ & $\sqrt{ }$ & $\sqrt{ }$ & $\sqrt{1}$ & $\sqrt{ }$ & $\sqrt{ }$ & n.p. & $\sqrt{ }$ & $\sqrt{1}$ & $\sqrt{ }$ & $\sqrt{ }$ ? & n.p. & $\sqrt{ }$ & $\sqrt{ }$ & $\sqrt{ }$ & n.p. & 3 \\
\hline $\begin{array}{l}\text { L. bolanderi } \\
\text { (WOO) }\end{array}$ & MBL & n.p. & $\sqrt{ }$ & n.p. & $\sqrt{ }$ & n.p. & $\sqrt{ }$ & $\sqrt{ }$ & n.p. & n.p. & $\sqrt{ }$ & $\checkmark$ & $\sqrt{ }$ & $\sqrt{ }$ & $\sqrt{ }$ & n.p. & n.p. & n.p. & n.p. & n.p. & 4 \\
\hline $\begin{array}{l}\text { L. bolanderi } \\
\text { (WOO) }\end{array}$ & KNG & n.p. & $\sqrt{ }$ & n.p. & $\sqrt{ }$ & n.p. & $\sqrt{ }$ & $\sqrt{1}$ & n.p. & n.p. & $\sqrt{1}$ & $\checkmark$ & $\sqrt{1}$ & $\sqrt{ }$ & $\sqrt{ }$ & n.p. & n.p. & n.p. & n.p. & n.p. & 3 \\
\hline $\begin{array}{l}\text { L. parviflorum } \\
\text { (TUR) }\end{array}$ & TUR & n.p. & n.p. & n.p. & n.p. & n.p. & n.p. & n.p. & n.p. & n.p. & n.p. & $\sqrt{ }$ & $\sqrt{ }$ & n.p. & n.p. & n.p. & n.p. & n.p. & n.p. & $\sqrt{ }$ & 3 \\
\hline $\begin{array}{c}\text { Synth (SED } \\
\text { mix1) }\end{array}$ & SED & & & $\sqrt{ }$ & & $\sqrt{ }$ & & & & & & $\sqrt{ }$ & & & & & & & & & 3 \\
\hline $\begin{array}{l}\text { Synth. (SED } \\
\text { mix2) }\end{array}$ & $\mathrm{MBL}$ & & & $\sqrt{ }$ & & $\sqrt{ }$ & & & & & & $\checkmark$ & & & & $\sqrt{ }$ & $\sqrt{ }$ & & & $\sqrt{ }$ & 1 \\
\hline $\begin{array}{l}\text { Synth (MBL } \\
\text { mix) }\end{array}$ & MBL & $\sqrt{ }$ & & & $\sqrt{ }$ & & & $\sqrt{ }$ & $\sqrt{ }$ & & & $\sqrt{ }$ & $\sqrt{ }$ & $\sqrt{ }$ & & & & & & & 2 \\
\hline $\begin{array}{l}\text { Synth (MBL } \\
\text { mix) }\end{array}$ & KNG & $\sqrt{ }$ & & & $\sqrt{ }$ & & & $\sqrt{ }$ & $\sqrt{ }$ & & & $\checkmark$ & $\sqrt{ }$ & $\sqrt{ }$ & & & & & & & 1 \\
\hline $\begin{array}{l}\text { Synth (WOO } \\
\operatorname{mix} 1)\end{array}$ & SED & & & $\sqrt{ }$ & $\sqrt{ }$ & & & & & & $\sqrt{ }$ & & $\sqrt{ }$ & & & & & & & & 1 \\
\hline Synth (mix 2) & TUR & & & & & & & & & & $\sqrt{ }$ & & & & & & & $\sqrt{ }$ & $\sqrt{ }$ & $\sqrt{ }$ & 2 \\
\hline
\end{tabular}

A check indicates reproducible EAD activity in female moths for a given compound; checks in red indicate EAD-responses to scent compounds that do not occur in the sympatric plant populations. Numbers refer to those peaks shown in Fig. 1. Compounds without numbers are not shown in Fig. 1. In all synthetic mixtures, all compounds were EAD active (i.e. the mixtures contain only those compounds that were indicated as being active)

SED Sedwick, CA; $M B L$ Marble falls trail, CA; WOO Woody, CA; KNG King's river, CA; TUR Turnbull, WA (for GPS coordinates see Methods section). TMP 6,10,14-trimethylpentadecan-2-one, $U i$ unidentified compound, n.p. compound not present in sample

${ }^{1}$ Because KNG flowers were not analyzed in this study, the information on the volatiles emitted by these flower were taken from Friberg et al. (2019) 
$50 \%$ of the effluent over a heated transfer line $\left(200{ }^{\circ} \mathrm{C}\right)$ into a purified and humidified air stream $\left(250 \mathrm{ml} \mathrm{min}^{-1}\right)$ in a stimulus delivery tube (10 mm diameter), which was directed over the excised antenna. EAD signals and FID responses were simultaneously recorded using Syntech software. Volatiles were assumed EAD-active if reproducible responses at the same retention time were seen in antennae of at least two individual Greya moths. For confirmation of responses with synthetic compounds, in case of clear responses, EAD responses of a single moth were considered sufficient (see Tables 1 and 2 for exact numbers). Volatiles were identified by gas chromatography with mass selective detection (GCMSD, see below). All putatively EAD-active volatiles were also directly tested for EAD activity as synthetic standards using the same GC-EAD system as for the natural samples. Synthetic volatiles were prepared in blends of compounds with non-overlapping retention times, in concentrations of $100 \mu \mathrm{g} \mathrm{ml}^{-1}$ in hexane.

\section{Compound identification}

Volatiles were identified using GC-MSD with liquid injection. Samples were injected with pulsed splitless mode $\left(200{ }^{\circ} \mathrm{C}\right)$ with 20 psi pulse pressure into a GC (Agilent $6890 \mathrm{~N}$, Agilent Technologies, Palo Alto, CA, USA). The GC oven was programmed to rise from a starting temperature of $50{ }^{\circ} \mathrm{C}$ to $230{ }^{\circ} \mathrm{C}$ at a rate of $10^{\circ} \mathrm{C} \mathrm{min}{ }^{-1}$ and held at the final temperature for $20 \mathrm{~min}$ The $\mathrm{GC}$ was equipped with a DB-WAX column $(0.32 \mathrm{~mm}$ diameter, $0.25 \mu \mathrm{m}$ film thickness, $30 \mathrm{~m}$ length) and helium was used as carrier gas at a flow rate of $1.5 \mathrm{ml} \mathrm{min}{ }^{-1}$. The GC column was connected to a mass selective detector (Agilent MSD 5975, Agilent Technologies, Palo Alto, CA, USA). The ChemStation Enhanced Data Analysis program was used. Scanning was started after 4.6 min solvent delay, and ranged from $\mathrm{m} / \mathrm{z} 40$ to 400 . Compounds were tentatively identified by comparison of MS spectra obtained from the samples, with those from a reference library (NIST 05 library). For final

Table 2 GC-EAD active volatiles from floral extracts of Lithophragma, and a synthetic, racemic sample of 6,10,14-trimethylpentadecan-2-one (TMP), analyzed in concentration of 100 and $1 \mu \mathrm{g} \mathrm{ml}^{-1}$; only female moths were used; n.p. compound not present in sample. Ui: unidentified compound

\begin{tabular}{|c|c|c|c|c|c|c|c|}
\hline $\begin{array}{l}\text { Lithophragma } \\
\text { species } \\
\text { (population) }\end{array}$ & $\begin{array}{l}\text { Moth } \\
\text { pop. }\end{array}$ & $\begin{array}{l}n \\
5\end{array}$ & $\begin{array}{l}0 \\
5\end{array}$ & 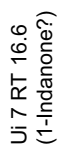 & 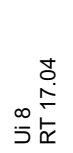 & $\sum_{i}^{n}$ & 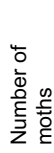 \\
\hline L. cymbalaria (SED) & SED & n.p. & n.p. & n.p. & n.p. & $\checkmark$ & 4 \\
\hline L. parviflorum (TUR) & TUR & $\sqrt{ }$ & $\sqrt{ }$ & v & $\sqrt{ }$ & $\sqrt{ }$ & 4 \\
\hline L. bolanderi (MBL) & TUR & n.p. & n.p. & $\checkmark$ & n.p. & $\checkmark$ & 2 \\
\hline L. cymbalaria (SED) & TUR & n.p. & n.p. & n.p. & n.p. & $\sqrt{ }$ & 2 \\
\hline Synthetic TMP & TUR & & & & & v & 2 \\
\hline Synthetic TMP & SED & & & & & $\checkmark$ & 2 \\
\hline
\end{tabular}

identification and quantification, synthetic standards of all compounds were analyzed and retention times and total mass spectrum of synthetic standards were compared with those of natural samples. Those compounds for which no reference standards were available, but spectra comparison yielded a match of above $90 \%$ quality, were judged as tentatively identified. Several EAD active compounds gave no useful MS fragmentation pattern for library comparison and were hence judged as unidentified. All chemical analyses (GC-EAD, GC-MS) were conducted at the United States Department of Agriculture, Agricultural Research Services, Albany, California.

\section{Quantification}

Quantification of volatiles was only tentatively possible, as most samples were collected from large bulk of flowers. To do so, synthetic reference standard were analyzed in two different concentrations to obtain calibration curves. Amounts of volatiles were then calculated from peak areas obtained from total ion chromatograms.

\section{Determination of stereoisomeric configuration of 6 , 10, 14-trimethylpentadecan-2-one (TPM-one)}

\section{Purification of flower extracts prior to stereochemical analysis}

The flower extracts were purified by liquid chromatography (LC) on pre-conditioned $500 \mathrm{mg}$ solid phase extraction column (SPE, Chromabond) using gradient elution in steps of $1 \%$ increase of ethyl acetate in pentane $(0-15 \%)$, each fraction consisted of a volume of $750 \mu \mathrm{l}$. SPE conditioning was done with ethyl acetate $(1.5 \mathrm{ml}), 10 \%$ ethyl acetate in pentane $(1.5 \mathrm{ml})$ and pentane $(1.5 \mathrm{ml})$. All SPE fractions were analysed by means of GC-MS and fractions containing 6,10,14-trimethylpentadecan-2-one were combined, and solvent were reduced in volume prior to reduction and derivatization.

\section{Reduction and derivatization of 6,10 , 14-trimethylpentadecan-2-one (TMP-one) fraction}

For L. bolanderi and L. parviflorum ketone fractions 3-6 were collected (containing mostly ketones), pooled and reduced to alcohol with $\mathrm{LiAlH}_{4}$ in $\mathrm{Et}_{2} \mathrm{O}$ (1 M solution) and subjected to SPE purification prior to derivatization. SPE fractions were analyzed and 6, 10, 14-trimethylpentadecan2 -ol was found in fractions 8-11. Due to the low concentration of the ketone in the L. cymbalaria extract, reduction to alcohol was performed without initial SPE purification. The SPE fractions containing reduced TMP-one were concentrated by means of evaporating solvent under a stream of 
13

A: L. bolanderi (MBL) flower

KNG moth

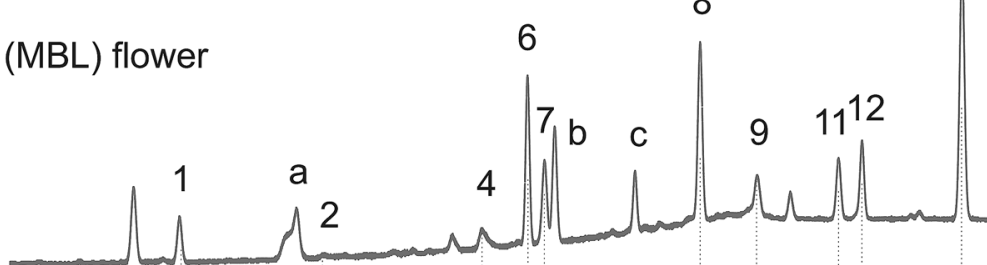

14

FID

EAD

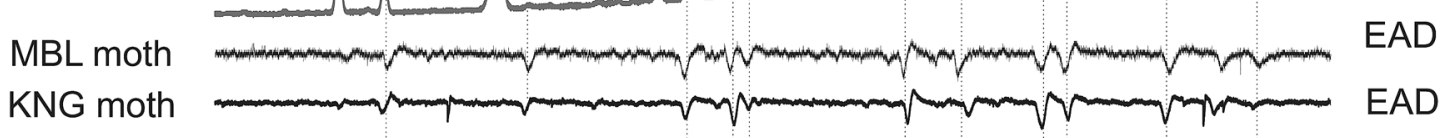

B: L. bolanderi (WOO) flower

a
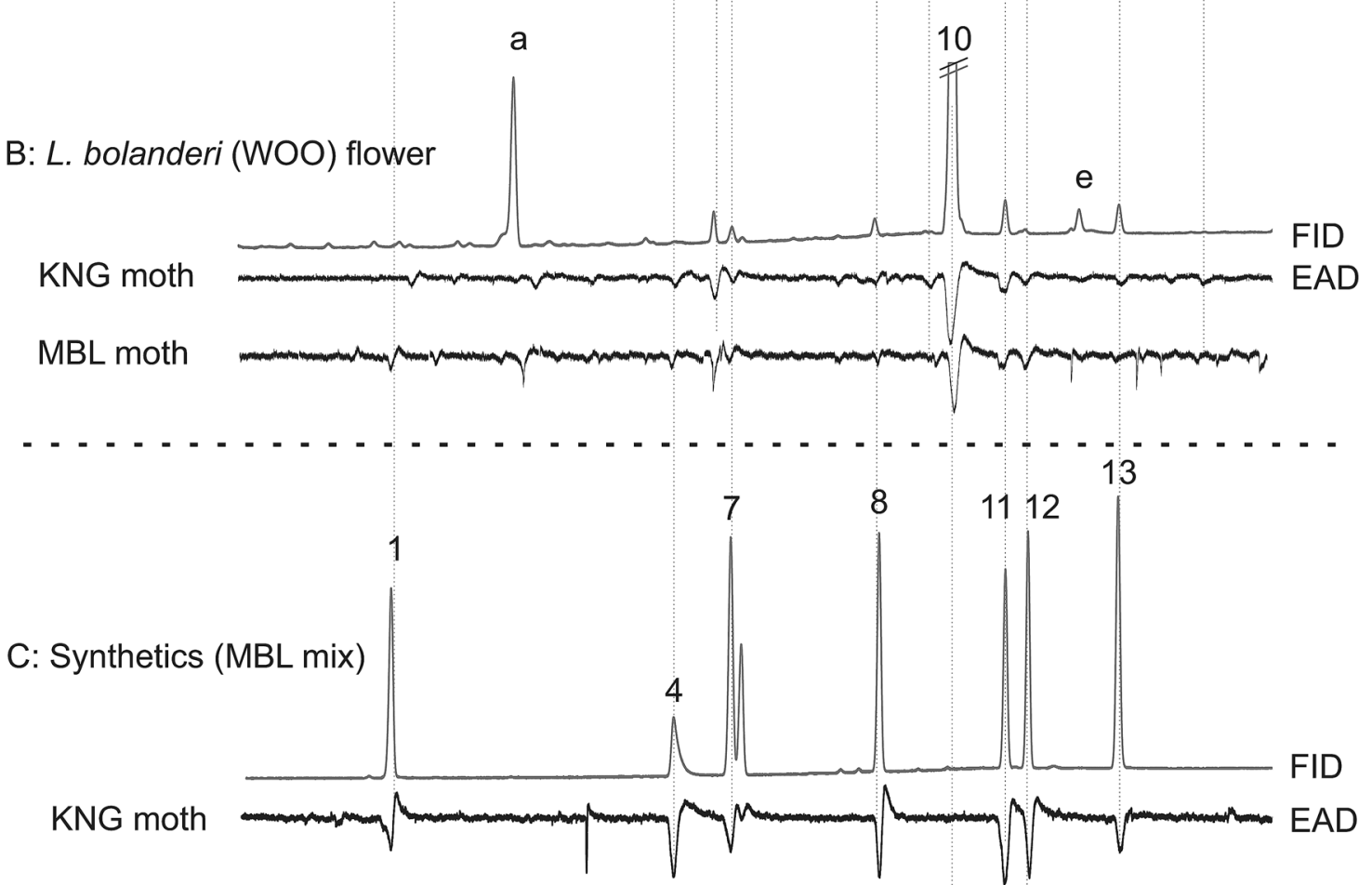

13

D: Synthetics (WOO \& MBL)

$8 \quad 1112$

EAD

FID

EAD

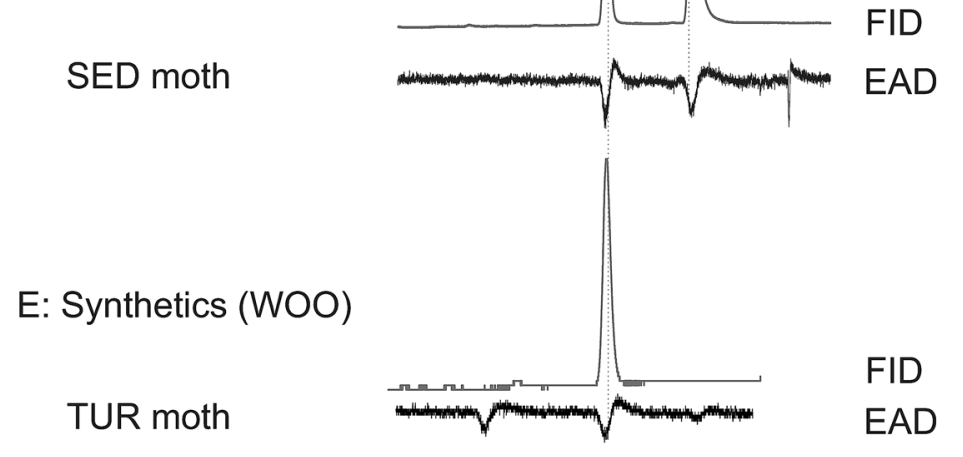

Argon gas. Dry cyclohexane $(50 \mu \mathrm{l})$ was added to the vial containing the purified extract and subsequently was $1 \%$ pyridine in cyclohexane $(65 \mu \mathrm{l})$ and $1 \%(S)$-2-acetoxypropionyl chloride in dichloromethane $(100 \mu \mathrm{l})$ added, the resulting mixture was heated at $80{ }^{\circ} \mathrm{C}$ for $30-60$ min under argon atmosphere (Figure S1). A needle was inserted into the 
४Fig. 1 Examples of gas chromatographic analyses with electroantennographic detection (GC-EAD) with different Lithophragma floral headspace samples $(\mathbf{a}, \mathbf{b})$ and synthetic mixtures $\left(\mathbf{c}-\mathbf{e} ; 100 \mu \mathrm{g} \mathrm{ml}^{-1}\right)$, and antennae of female Greya politella moths from different populations. a headspace sample of $L$. bolanderi (MBL) tested on sympatric (MBL) and allopatric (KNG) moths; b headspace sample of $L$. bolanderi (WOO) tested on allopatric moths (MBL, KNG). The analyses show that moths, irrespective of their origin, respond to the same compounds in the volatile samples. c Synthetic $L$. bolanderi (MBL) mix tested on KNG antennae, showing responses to all compounds, of which two (camphor and 2-phenylethyl acetate) do not occur in local KNG flowers (Friberg et al. 2019). d 1,4-dimethoxybenzene and 2-phenylethyl acetate tested on SED moths, and E: 1,4-dimethoxybenzene tested on TUR moths. In local SED and TUR flowers, both compounds do not occur. Numbers refer to names of EAD-active compounds in Table 1: letters refer to compounds without detectable EAD activity: (a) diacetone alcohol, (b) benzaldehyde, (c) caryophyllene, (d) methyl benzoate, (e) benzyl alcohol. FID flame ionization detector

septum of the vial and the solvent was allowed to evaporate before allowing the vial to reach room temperature. $\mathrm{HCl}$ $(1 \mathrm{M}, 200 \mu \mathrm{l})$ and pentane $(1 \mathrm{ml})$ was added, the organic layer was subsequently dried over $\mathrm{Na}_{2} \mathrm{SO}_{4}$ (anhydr.) in a Pasteur pipette. Solvent was either reduced to approximately $50 \mu \mathrm{l}$ and the sample was analyzed as described below or the solvent was evaporated completely and the sample dissolved in cyclohexane prior to analysis.

\section{Stereochemical analysis of purified extracts}

GC-MS in selected ion monitoring mode was utilized for chemical identification of reduced and derivatized stereoisomers of TMP-one. A GC (HP 6890, Agilent Technologies, Santa Clara, CA, USA) coupled to a mass selective detector HP 5973 N MS (Agilent Technologies, Santa Clara, CA, USA) and ChemStation Enhanced Data Program Analysis was utilized for the analysis. The sample $(1 \mu \mathrm{l})$ was injected in splitless mode at $250{ }^{\circ} \mathrm{C}$. The mass spectrometer was operated under electron impact (EI) ionization, the transfer line was maintained at $250{ }^{\circ} \mathrm{C}$ and the mass spectrometer at $250^{\circ} \mathrm{C}$. Selected ion monitoring (SIM) (m/z 105, 115, 133, $210,252)$ was used for identification of the $(S)$-2-acetoxypropionyl derivatives of 6, 10, 14-trimethylpentadecan-2-ol (Hedenström et al. 2015; Nieberding et al. 2008; Wallin et al. 2020). The GC was equipped with an achiral FactorFOUR VF-23 ms polar GC column from Varian $(0.25 \mathrm{~mm}$ diameter, $0.25 \mu \mathrm{m}$ film thickness, $30 \mathrm{~m}$ long) for separation of all isomers and helium was used as carrier gas at a flow rate of $1 \mathrm{ml} \mathrm{min}^{-1}$. The $\mathrm{GC}$ oven was programmed to rise from a starting temperature of $50{ }^{\circ} \mathrm{C}$ by $10{ }^{\circ} \mathrm{C} \mathrm{min}^{-1}$ up to $110{ }^{\circ} \mathrm{C}$, from $110{ }^{\circ} \mathrm{C}$ by $0.01{ }^{\circ} \mathrm{C} \mathrm{min}{ }^{-1}$ up to $115{ }^{\circ} \mathrm{C}$, and from $115^{\circ} \mathrm{C}$ by $10^{\circ} \mathrm{C} \mathrm{min}^{-1}$ up to $230^{\circ} \mathrm{C}$, and held at $230{ }^{\circ} \mathrm{C}$ for $10 \mathrm{~min}$.
Preparation of reference compounds. (2R/S,6R/S,10R/ S)-6,10,14-trimethylpentadecan-2-ol

$(2 E, 7 R / S, 11 R / S)-(3,7,11,15)-T e t r a m e t h y l-2$-hexadecen-1-ol $((2 E, 7 R / S, 11 R / S)$-phytol) (Sigma Aldrich) was oxidized at room temperature by sodium periodate and catalytic amount of ruthenium (III) chloride, the obtained ketone was reduced with lithium aluminum hydride in diethyl ether resulting in a mixture of eight isomers of TMP-ol (synthetic scheme Figure S1; Nieberding et al. 2008). The synthetic mixture was derivatized and analyzed according to the same method as the purified flower extracts.

\section{(2S,6R,10R)-6,10,14-Trimethylpentadecan-2-ol and $(2 R, 6 R, 10 R)-6,10,14$-trimethylpentadecan-2-ol}

$(2 E, 7 \underline{R}, 11 R)$-phytol (TCI America) was treated as described above, resulting in a mixture of $(2 R, 6 R, 10 R)$ - and $(2 S, 6 R, 10 R)$-TMP-ol. The isomeric mixture was subjected to enzymatic resolution by Candida antarctica lipase-B (CALB, Roche Diagnostics batch 90750729) as catalyst and vinyl acetate (Sigma Aldrich) as acyl-donor. With this method the $(2 R)$-alcohol is acetylated and therefore the two isomers are easily separated by means of flash chromatography on silica gel with gradient elution with increasing ratio of ethyl acetate in cyclohexane. The obtained $(2 R)$-acetate was hydrolyzed in $\mathrm{KOH} /$ methanol furnishing the alcohol. A diastereomeric purity of $99.8 \%$ for $(-)-(2 R, 6 R, 10 R)$-TMP-ol and $97.8 \%$ diastereomeric purity of $(+)-(2 S, 6 R, 10 R)$-TMP-ol was obtained (Nieberding et al. 2012). The stereoisomerically pure isomers were derivatized and analyzed according to the same method as the purified flower extracts. (Synthetic scheme see Figure S1).

\section{Results}

\section{EAD-active compounds}

Greya moths detected a total of 23 volatiles from Lithophragma scent samples (headspace and extracts). In all headspace samples, 19 compounds were found to be EAD active (Table 1; Fig. 1). We chemically identified fifteen of these compounds and confirmed their EAD activity using synthetic standards. Four remained unidentified (Table 1).

In the floral extracts, five compounds were consistently EAD active, of which we identified one as 6,10,14-trimethylpentadecan-2-one (TMP), and another one tentatively as 2,3-dihydro-1H-inden-1-one (i.e. 1-indanone; Fig. 2; Table 2); three compounds remained unidentified. TMP was found in extracts of all species analyzed, and in the headspace samples of $L$. parviflorum (TUR). Whereas in extract samples it is not sure whether the presence of TMP is an 
artefact from the wounding of the tissue, in headspace samples, only non-injured tissue was sampled and thus TMP can be considered as a volatile being emitted in small amounts from intact flowers.

Whereas TMP and 1-indanone have not been documented before in Lithophragma, most of the other active compounds represent a subset of the previously detected volatiles in this plant genus (Friberg et al. 2019). We found that most major compounds found in our headspace samples were active, with the notable exception of $\alpha$-pinene, which was a main compound in the headspace of L. parviflorum (TUR; data not shown; Friberg et al. 2013) but did not trigger EAD responses in moths from the same population. Headspace samples from TUR were not tested with moths from any other population (see Table 1), and thus we do not know whether $\alpha$-pinene was active in moths of other populations.

\section{Divergence of olfactory detection among populations}

We did not find any evidence that Greya moths responded differently to volatiles from sympatric or allopatric Lithophragma species/populations (Table 3), despite the fact that Lithophragma species differed greatly in volatile composition (both quantitatively and qualitatively). Generally, all moths responded to all EAD-active major compounds, no matter whether they were present in sympatric Lithophragma species or not (Table 3). As the most obvious example, 1,4-dimethoxybenzene (compound no. 10 in Fig. 1) was only present in Lithophragma samples from WOO, but proved to be active when those samples were tested on moths from MBL and KNG, and as synthetic compound on moths from SED and TUR (Fig. 1B, D, E).

\section{Stereoisomeric composition of TMP}

By applying methods developed by previous studies (Eltz et al. 2010; Hedenström et al. 2015; Wallin et al. 2020) we showed that all analyzed Lithophragma species produced the $(6 R, 10 R)$-enantiomer of TMP-one. There was no difference in enantiomeric composition of TMP in the floral extracts of the different Lithophragma species (Fig. 3). The extra peak (RT 379.88) in the chromatogram of L. bolanderi (Fig. 3c) is not a match to any of the eight TMP-ol isomers when comparing retention time and evaluating the mass spectra fragmentation pattern (Figure S2). All eight isomers of the derivatized TMP-ol show the same fragmentation pattern in SIM mode, therefore we have strong evidence based on retention time and fragmentation pattern that the extra peak is not a TMP-ol isomer.

\section{Discussion}

Despite the fact that insects specialized to host plants often use a narrow set of uncommon key volatiles for host location, we show here that olfactory detection of Lithophragma volatiles in Greya moths is generalized. This is evidenced by (i) the fact that moths responded to a large range of different compounds, including different compound classes, and (ii) that Greya moths from different regions detect even those volatiles that are not produced by their local Lithophragma host species. For example, moths from TUR respond to 1,4-dimethoxybenzene (Fig. 1E), which is not found in the local TUR species L. parviflorum (Friberg et al. 2013, 2014). The closest Lithophragma that emit this compound are $L$. bolanderi and $L$. campanulatum populations growing $800 \mathrm{~km}$ south of TUR. As another example, 2-phenylethyl acetate, which was found in $L$. bolanderi from MBL but not in $L$. cymbalaria from SED, was active in moths from SED (Fig. 1D). These results indicate that preferences in moths for local host species (Friberg et al. 2014) are not mediated by the olfactory detection of species-specific key volatiles in the moths' antennae, but are likely based on pattern recognition of volatile bouquets in the brain, which is a common principle in butterflies and moths (de Fouchier et al. 2017).

Very few studies have addressed variation in olfactory detection among populations or closely related species of insects, but the available studies show that both conservative maintenance of receptor sensitivity (Eltz et al. 2006), as well as rapid divergence (de Bruyne et al. 2010), is possible. Conserved receptor function was found, for example, in males of different euglossine bee species, where broad and overlapping detection of volatiles of tibial extracts was shown by GC-EAD, despite the fact that bees respond behaviorally in a highly specific manner to tibial extracts (Eltz et al. 2006). Similarly, two species of polyphagous fruit and flower feeding beetles of the genus Pachnoda, which live in different habitats, share olfactory receptors tuned towards the same volatiles (Bengtsson et al. 2011), and different species of bee- and moth pollinators respond similarly to Salix-volatiles (Jürgens et al. 2014). In the genus Drosophila, although ester-responsive olfactory neurons are generally conservative and show little functional change, some neuron classes evolve rapidly, showing different responsiveness among species (de Bruyne et al. 2010). Rapid evolution of olfactory receptor genes has also been shown to accompany host specialization in another lineage of Drosophila (McBride 2007), likely driven by adaptive evolution (McBride and Arguello 2007). In yet other insects, differences among species may evolve through changes in the number of compounds used for host detection. A recent study on two Oedemeridae beetles of the same genus has shown that EAD-detection of Fragaria volatiles differs 


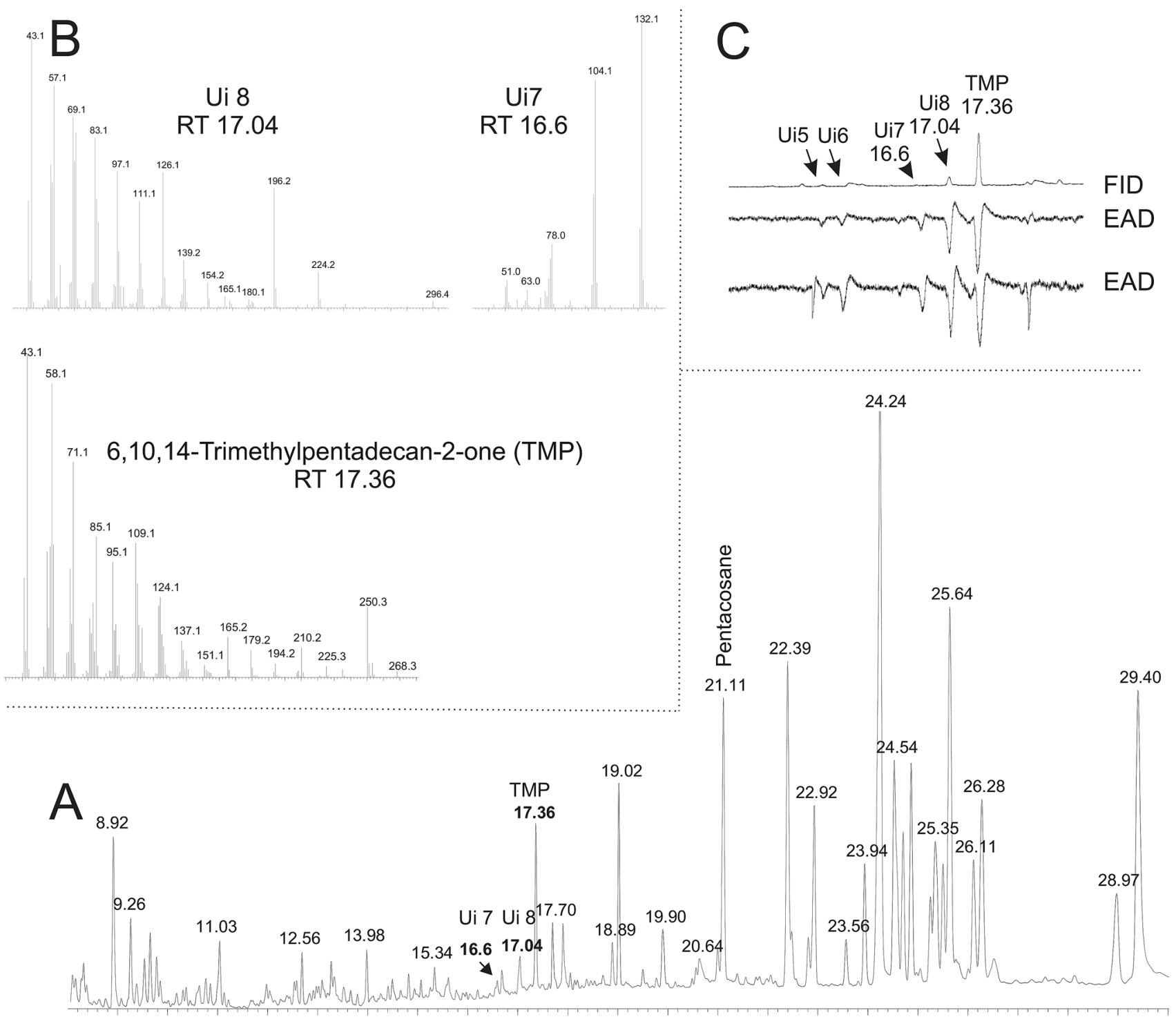

Fig. 2 a Total ion chromatogram of the ketone fraction of Lithophragma parviflorum (TUR) floral extracts (300 flowers) obtained by SPE fractionation of the crude extract (see methods for details). Retention times of EAD-active compounds are given in bold. b MS spectra of three EAD-active compounds found in the sample. c The output of GC-EAD analysis of the same sample showing flame

among them, with one species detecting more compounds than the other (Blazyte-Cereskiene et al. 2019).

Our study shows that despite population-specific preferences of flower volatiles by moths (Friberg et al. 2014), the underlying qualitative olfactory receptor sensitivity (i.e. responding to compounds or not) of the moths is conserved and does not show population-specific divergence. This lack of divergence is in contrast to morphological traits in woodland stars and Greya moths, that diversify in a co-evolutionary manner depending on the nature of their interactions (Thompson et al. 2013). The lack of divergence ionization detector (FID) trace and electroantennographic detection (EAD) trace of two antennae of female Greya politella moths from TUR. The five active compounds are indicated by arrows and/or retention times. For UI 1 and UI 2 no proper MS spectra could be obtained with GC-MS analysis

in qualitative olfactory receptor sensitivity may stem either from selection on broad olfactory sensitivity or from lack of suitable genetic variation. Selection for broad olfactory sensitivity in interactions may result from plant populations producing complex and variable floral volatile bouquets that may potentially evolve rapidly (Gervasi and Schiestl 2017; Ramos and Schiestl 2020). Under these conditions, reliance on one or a few compounds could be selectively disadvantageous. For example, some populations of Lithophragma show polymorphisms or patchy differences in compounds such as 1,4-dimethoxybenzene (Friberg et al. 2019). 
Table 3 Summary of EAD activity of Lithophragma volatiles in female Greya politella moths of different populations (only chemically identified volatiles are shown)

\begin{tabular}{|c|c|c|c|c|c|c|c|c|c|c|c|c|c|c|c|c|}
\hline $\begin{array}{l}\text { Greya } \\
\text { pop. }\end{array}$ & $\begin{array}{l}\text { Hexeny } \\
\text { I } \\
\text { acetate }\end{array}$ & $\begin{array}{l}\text { Nonana } \\
\text { l }\end{array}$ & $\begin{array}{l}\text { Decana } \\
\text { I10 }\end{array}$ & Linalool & $\begin{array}{l}\text { Camph } \\
\text { or }\end{array}$ & $\begin{array}{l}\text { Acetop } \\
\text { henone }\end{array}$ & $\begin{array}{l}1,4- \\
\text { Dimeth } \\
\text { oxyben } \\
\text { zene }\end{array}$ & $\begin{array}{l}\text { Methyl } \\
\text { salicylat } \\
\mathrm{e}\end{array}$ & $\begin{array}{l}\text { Phenyl } \\
\text { ethyl } \\
\text { acetate }\end{array}$ & $\begin{array}{l}\text { Phenyl } \\
\text { ethyl } \\
\text { alcoho. }\end{array}$ & $\begin{array}{l}\text { Dimeth } \\
\text { yl } \\
\text { salicylat } \\
\text { e }\end{array}$ & $\begin{array}{l}2- \\
\text { Amino } \\
\text { benzald } \\
\text { ehyde }\end{array}$ & $\begin{array}{l}\text { Methyl } \\
\text { anthran } \\
\text { ilate }\end{array}$ & $\begin{array}{l}\text { Cinnam } \\
\text { ic } \\
\text { alcohol }\end{array}$ & TMP & $\begin{array}{l}\text { No. of } \\
\text { moths }\end{array}$ \\
\hline SED & n.t. & $\sqrt{ }$ & $\sqrt{ }$ & $\sqrt{ }$ & n.t. & n.t. & $\sqrt{ }$ & $\sqrt{ }$ & $\sqrt{ }$ & n.t. & $\sqrt{ }$ & $\sqrt{ }$ & $\sqrt{ }$ & n.t. & $\sqrt{ }$ & 8 \\
\hline MBL & $\sqrt{ }$ & $\sqrt{ }$ & $\sqrt{ }$ & $\sqrt{ }$ & $\sqrt{ }$ & $\sqrt{ }$ & $\sqrt{ }$ & $\sqrt{ }$ & $\sqrt{ }$ & $\sqrt{ }$ & $\sqrt{ }$ & $\sqrt{ }$ & $\sqrt{ }$ & $\sqrt{ }$ & $\sqrt{ }$ & 10 \\
\hline KNG & $\sqrt{ }$ & $\sqrt{ }$ & $\checkmark$ & $\sqrt{ }$ & $\sqrt{ }$ & $\sqrt{ }$ & $\sqrt{ }$ & $\checkmark$ & $\sqrt{ }$ & $\sqrt{ }$ & n.t. & $\sqrt{ }$ & $\sqrt{ }$ & $\checkmark$ & $\sqrt{ }$ & 7 \\
\hline TUR & n.t. & n.t. & n.t. & n.t. & n.t. & n.t. & $\sqrt{ }$ & $\sqrt{ }$ & $\sqrt{ }$ & n.t. & n.t. & n.t. & $\checkmark$ & $\sqrt{ }$ & $\sqrt{ }$ & 5 \\
\hline
\end{tabular}

The table shows the detected EAD active compounds, both in natural samples and synthetic compounds. A check indicates EAD activity, red checks indicate activity of compounds that normally do not occur in the plant populations co-occurring with the respective moths. Number of moths is the total number of moths used to detect the activity of all tested compounds; $n$.t. not tested. TMP 6,10,14-trimethylpentadecan-2-one

Alternatively, low genetic variability in receptor specificity may constrain the evolution of this trait in Greya moths. Our results suggest that the next problem to solve in understanding the mediation of these interactions is why Lithophragma species and populations make such complex and variable floral bouquets and why Greya remain so conservative in their olfactory receptor sensitivity.

One volatile not previously detected in Lithophragma, 6,10,14-trimethylpentadecan-2-one (TMP), was found here in low amounts in headspace samples and extracts, and was highly active in Greya olfactory neurons. This compound is a breakdown product of phytol, and commonly found in plant essential oils (Eltz et al. 2010), but rarely detected in headspace samples of flowers, likely because of its relatively low volatility. The enantiomeric composition of this compound has been shown to be important in its attractiveness for euglossine bees (Eltz et al. 2010). All studies that have assessed the enantiomeric configuration of this compound, have detected this compound only in the $(6 R, 10 R)$ enantiomeric configuration (Schulz et al. 2011; Wallin et al. 2020), but none so far has investigated geographic variation in enantiomer composition. Our study shows that TMP occurs in the $(6 \mathrm{R}, 10 \mathrm{R})$-enantiomeric composition in all studied Lithophragma species, suggesting it plays no role in the region-specific preferences of Greya moths. Quantitative studies on the variation of relative amounts of different enantiomers may nevertheless show differences among populations that may contribute to preferences of Greya moths.

An interesting aspect of TMP and its corresponding alcohol is its function as sex pheromone in diverse groups of Lepidoptera (Hedenström et al. 2015; Schulz et al. 2011). Our finding of EAD activity of this compound in Greya politella, a species of the ancestral Lepidoptera lineage of Monotrysia, suggest that the use of this compound may have originated very early in the evolutionary history of this insect order. TMP may serve pheromonal functions in Greya, but our initial GC-EAD analyses with female and male body extracts using male and female antennae failed to detect the compound in the insect samples (data not shown). More detailed studies are deemed necessary, however, to investigate the potential production, or use of TMP as pheromone by Greya moths. Earlier analyses have shown that plant volatiles and pheromones overlap chemically in many insect groups (Schiestl 2010), and the pheromonal functions of TMP in more derived Lepidoptera may have evolved from its initial function as a host detection cue in ancestral lineages.

In conclusion, our study shows that a moth species of the ancestral lineage of Monotrysia, highly specialized on its host plant, is able to detect a broad range of volatiles, and seems to lack species- or region-specific divergence in olfactory neuron specificity, as detectable by GC-EAD. Our results using the GC-EAD method focus on qualitative differences in detection, but do not allow to precisely quantitate differences in receptor sensitivity. Therefore, follow-up studies using more quantitative methods such as EAG or single sensillum recording are needed to assess differences in receptor fine-tuning or abundances of different receptor types in moth antennae. Future studies should also try to elucidate the behavioral activity of individual EAD-active compounds, to identify potential key compounds triggering attraction and oviposition behavior, and potentially mate finding.

Supplementary Information The online version contains supplementary material available at https://doi.org/10.1007/s11829-021-09809-5.

Acknowledgements We thank Wai Gee for his invaluable help with GC-EAD and GC-MS analyses, Mia Waters and Daniela M Ruiz for help with fieldwork. The study was supported by a sabbatical leave and funds from the University of Zürich granted to FPS, the Jean H. Langenheim Endowed Chair funds to JNT, and USDA-ARS Research Project 6036-22000-028 and 2030-42000-039 (JB). MF was supported by the Royal Swedish Academy of Sciences and the STINT research council. EW was financially supported by the Regional development fund for Västernorrland and Jämtland/Härjedalen county and the Swedish Agency for Economic and Regional Growth.

Funding Open Access funding provided by Universität Zürich. The study was supported by a sabbatical leave and funds from the University of Zürich granted to FPS, the Jean H. Langenheim Endowed Chair funds to JNT, and USDA-ARS Research Project 6036-22000-028 and 2030-42000-039 (JB). MF was supported by the Royal Swedish Academy of Sciences and the STINT research council. EW was financially supported by the Regional development fund for Västernorrland and 
A

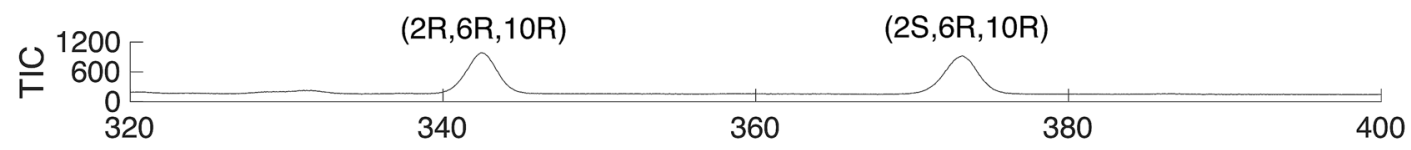

B

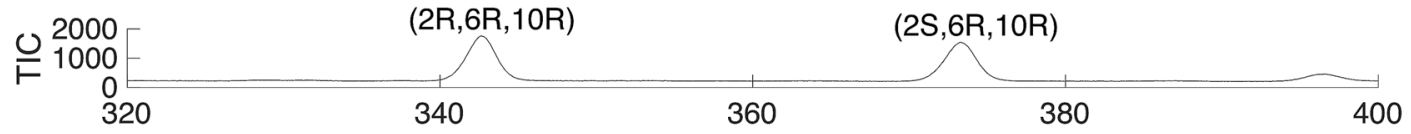

C

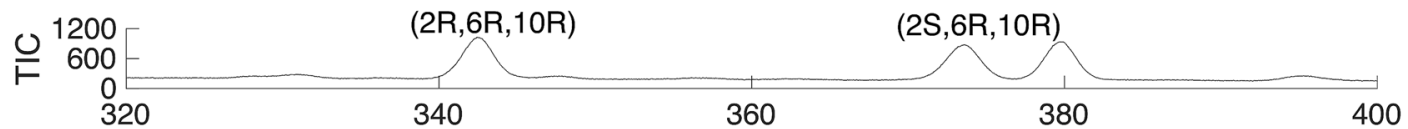

$(2 \mathrm{R}, 6 \mathrm{R} / \mathrm{S}, 10 \mathrm{R} / \mathrm{S})$

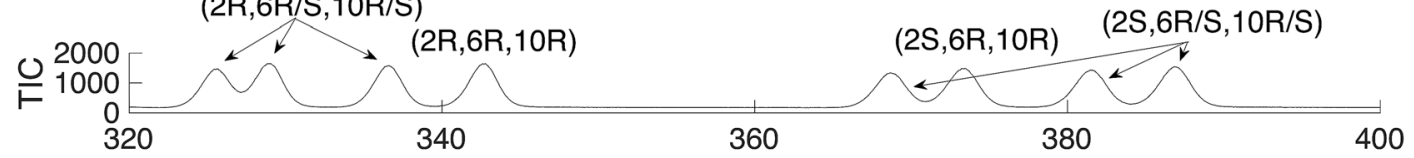

E

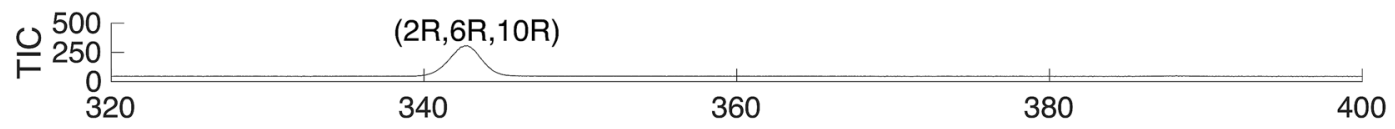

$\mathrm{F}$

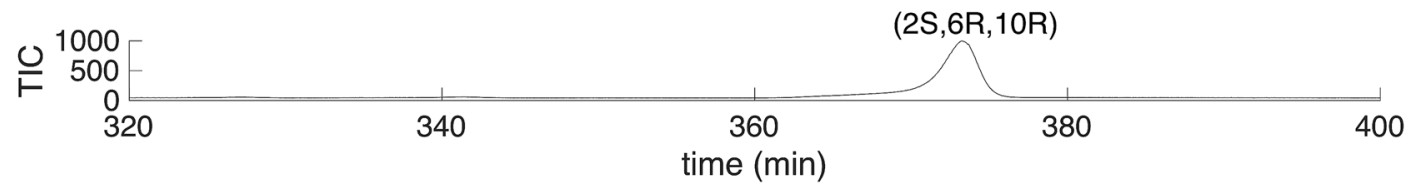

Fig. 3 Selected ion chromatogram of reduced and derivatized a $L$. cymbalaria, b $L$. bolanderi, $\mathbf{c} L$. parviflorum, $\mathbf{d}$ derivatized synthetic mixture of 6,10,14-trimethylpentadecan-2-ol, e derivatized synthetic

Jämtland/Härjedalen county and the Swedish Agency for Economic and Regional Growth.

\section{Compliance with ethical standards}

Conflict of interest There are no conflicts of interest.

Consent to participate Consent is granted.

Consent for publication Consent is granted.

Open Access This article is licensed under a Creative Commons Attribution 4.0 International License, which permits use, sharing, adaptation, distribution and reproduction in any medium or format, as long as you give appropriate credit to the original author(s) and the source, provide a link to the Creative Commons licence, and indicate if changes were made. The images or other third party material in this article are included in the article's Creative Commons licence, unless indicated otherwise in a credit line to the material. If material is not included in the article's Creative Commons licence and your intended use is not permitted by statutory regulation or exceeds the permitted use, you will need to obtain permission directly from the copyright holder. To view a copy of this licence, visit http://creativecommons.org/licenses/by/4.0/.
$(2 R, 6 R, 10 R)-6,10,14$-trimethylpentadecan-2-ol and $\mathbf{f}$ derivatized synthetic $(2 S, 6 R, 10 R)-6,10,14-$ trimethylpentadecan-2-ol

\section{References}

Bengtsson JM et al (2011) Conserved, highly specialized olfactory receptor neurons for food compounds in 2 congeneric scarab beetles, Pachnoda interrupta and Pachnoda marginata. Chem Senses 36:499-513. https://doi.org/10.1093/chemse/bjr002

Blazyte-Cereskiene L, Apsegaite V, Buda V (2019) The choice between flowers of closely related plant species by generalist pollinator: identification of relevant VOCs. Arthropod-Plant Interact 13:735743. https://doi.org/10.1007/s11829-019-09702-2

Bohman B, Karton A, Flematti GR, Scaffidi A, Peakall R (2018) Structure-activity studies of semiochemicals from the spider orchid caladenia plicata for sexual deception. J Chem Ecol 44:436-443. https://doi.org/10.1007/s10886-018-0946-0

Borg-Karlson AK, Tengo J, Valterova I, Unelius CR, Taghizadeh T, Tolasch T, Francke W (2003) (S)-(+)-linalool, a mate attractant pheromone component in the bee colletes cunicularius. J Chem Ecol 29:1-14

Bruce TJA, Pickett JA (2011) Perception of plant volatile blends by herbivorous insects - finding the right mix. Phytochemistry 72:1605-1611. https://doi.org/10.1016/j.phytochem.2011.04.011

Burger H, Dötterl S, Haberlein CM, Schulz S, Ayasse M (2012) An arthropod deterrent attracts specialised bees to their host plants. Oecologia 168:727-736. https://doi.org/10.1007/s0044 2-011-2136-4 
Chen C, Song Q (2008) Responses of the pollinating wasp ceratosolen solmsi marchali to odor variation between two floral stages of Ficus hispida. J Chem Ecol 34:1536-1544. https://doi. org/10.1007/s10886-008-9558-4

de Bruyne M, Smart R, Zammit E, Warr CG (2010) Functional and molecular evolution of olfactory neurons and receptors for aliphatic esters across the Drosophila genus. J Comp Physiol A 196:97-109. https://doi.org/10.1007/s00359-009-0496-6

de Fouchier A et al (2017) Functional evolution of Lepidoptera olfactory receptors revealed by deorphanization of a moth repertoire . Nature Commun 8:11. https://doi.org/10.1038/ncomms15709

Dötterl S, Wolfe LM, Jürgens A (2005) Qualitative and quantitative analyses of flower scent in Silene latifolia. Phytochemistry 66:203-213

Eltz T, Ayasse M, Lunau K (2006) Species-specific antennal responses to tibial fragrances by male orchid bees. J Chem Ecol 32:71-79

Eltz T, Hedenstrom E, Bang J, Wallin EA, Andersson J (2010) (6R, 10R)-6,10,14-trimethylpentadecan-2-one, a dominant and behaviorally active component in male orchid bee fragrances. J Chem Ecol 36:1322-1326. https://doi.org/10.1007/s1088 6-010-9873-4

Friberg M, Schwind C, Guimaraes PR Jr, Raguso RA, Thompson JN (2019) Extreme diversification of floral volatiles within and among species of Lithophragma (Saxifragaceae). Proc Natl Acad Sci U S A 116:4406-4415. https://doi.org/10.1073/pnas.18090 07116

Friberg M, Schwind C, Raguso RA, Thompson JN (2013) Extreme divergence in floral scent among woodland star species (Lithophragma spp.) pollinated by floral parasites. Ann Bot 111:539 550. https://doi.org/10.1093/aob/mct007

Friberg M, Schwind C, Roark LC, Raguso RA, Thompson JN (2014) Floral scent contributes to interaction specificity in coevolving plants and their insect pollinators. J Chem Ecol 40:955-965. https ://doi.org/10.1007/s10886-014-0497-y

Friberg M, Waters MT, Thompson JN (2017) Nutrient availability affects floral scent much less than other floral and vegetative traits in Lithophragma bolanderi. Ann Bot 120:471-478. https://doi. org/10.1093/aob/mcx069

Gervasi DD, Schiestl FP (2017) Real-time divergent evolution in plants driven by pollinators. Nature Commun. https://doi.org/10.1038/ ncomms 14691

Hedenström E et al (2015) Stereoisomeric analysis of 6,10,14-Trimethylpentadecan-2-ol and the corresponding ketone in wing extracts from African bicyclus butterfly species. J Chem Ecol 41:44-51. https://doi.org/10.1007/s10886-014-0539-5

Huber FK, Kaiser R, Sauter W, Schiestl FP (2005) Floral scent emission and pollinator attraction in two species of Gymnadenia (Orchidaceae). Oecologia 142:564-575

Jones WD, Nguyen TAT, Kloss B, Lee KJ, Vosshall LB (2005) Functional conservation of an insect odorant receptor gene across 250 million years of evolution. Curr Biol 15:R119-R121. https://doi. org/10.1016/j.cub.2005.02.007

Jürgens A, Glück U, Aas G, Dötterl S (2014) Diel fragrance pattern correlates with olfactory preferences of diurnal and nocturnal flower visitors in Salix caprea (Salicaceae). Bot J Linn Soc 175:624-640. https://doi.org/10.1111/boj.12183

Knauer AC, Schiestl FP (2015) Bees use honest floral signals as indicators of reward when visiting flowers. Ecol Lett 18:135-143. https ://doi.org/10.1111/ele.12386

Kuzoff RK, Soltis DE, Hufford L, Soltis PS (1999) Phylogenetic relationships within Lithophragma (Saxifragaceae): hybridization, allopolyploidy, and ovary diversification. Syst Bot 24:598-615. https://doi.org/10.2307/2419645

Maia ACD et al (2012) The key role of 4-methyl-5-vinylthiazole in the attraction of scarab beetle pollinators: a unique olfactory floral signal shared by annonaceae and araceae. J Chem Ecol 38:10721080. https://doi.org/10.1007/s10886-012-0173-z

McBride CS (2007) Rapid evolution of smell and taste receptor genes during host specialization in Drosophila sechellia. Proc Natl Acad Sci USA 104:4996-5001. https://doi.org/10.1073/pnas.0608424104

McBride CS, Arguello JR (2007) Five drosophila genomes reveal nonneutral evolution and the signature of host specialization in the chemoreceptor superfamily. Genetics 177:1395-1416. https://doi. org/10.1534/genetics.107.078683

Metcalf RL, Metcalf ER, Mitchell WC, Lee LWY (1979) Evolution of olfactory receptor in oriental fruit fly Dacus dorsalis. Proc Natl Acad Sci USA 76:1561-1565. https://doi.org/10.1073/ pnas.76.4.1561

Milet-Pinheiro P, Ayasse M, Dobson HEM, Schlindwein C, Francke W, Dötterl S (2013) The chemical basis of host-plant recognition in a specialized bee pollinator. J Chem Ecol 39:1347-1360. https ://doi.org/10.1007/s10886-013-0363-3

Mohamed MA, Quisenberry SS, Moellenbeck DJ (1992) 6,10,14-Trimethylpentadecanon-2-one - a bermuda grass phagostimulant to fall armyworm (Lepidoptera, Noctuidae). J Chem Ecol 18:673682. https://doi.org/10.1007/bf00987827

Nieberding CM et al (2008) The male sex pheromone of the butterfly bicyclus anynana: towards an evolutionary analysis. PLoS ONE. https://doi.org/10.1371/journal.pone.0002751

Nieberding CM, Fischer K, Saastamoinen M, Allen CE, Wallin EA, Hedenstrom E, Brakefield PM (2012) Cracking the olfactory code of a butterfly: the scent of ageing. Ecol Lett 15(5):415-424

Raguso RA (2016) More lessons from linalool: insights gained from a ubiquitous floral volatile. Curr Opin Plant Biol 32:31-36. https:// doi.org/10.1016/j.pbi.2016.05.007

Ramos SC, Schiestl FP (2020) Evolution of floral frangrance is compromised by herbivory. Front Ecol Evol 8:30

Rich KA, Thompson JN, Fernandez CC (2008) Diverse historical processes shape deep phylogeographical divergence in the pollinating seed parasite Greya politella. Mol Ecol 17:2430-2448. https://doi. org/10.1111/j.1365-294X.2008.03754.X

Schaeffler I et al (2015) Diacetin, a reliable cue and private communication channel in a specialized pollination system. Sci Rep. https ://doi.org/10.1038/srep12779

Schiestl FP (2010) The evolution of floral scent and insect chemical communication. Ecol Lett 13:643-656

Schiestl FP (2015) Ecology and evolution of floral volatile-mediated information transfer in plants. New Phytol 206:571-577. https:// doi.org/10.1111/nph.13243

Schiestl FP, Dötterl S (2012) The evolution of floral scent and olfactory preferences in pollinators: coevolution or pre-existing bias? Evolution 66:2042-2055

Schiestl FP, Marion-Poll F (2002) Detection of physiologically active flower volatiles using gas chromatography coupled with electroantennography vol volume 21 . Analysis of taste and aroma. Springer Berlin Heidelberg, Berlin, Heidelberg

Schulz S, Yildizhan S, van Loon JJA (2011) The biosynthesis of hexahydrofarnesylacetone in the butterfly Pieris brassicae. J Chem Ecol 37:360-363. https://doi.org/10.1007/s10886-011-9939-y

Suinyuy TN, Donaldson JS, Johnson SD (2015) Geographical matching of volatile signals and pollinator olfactory responses in a cycad brood-site mutualism. Proc Roy Soc B Biol Sci. https:// doi.org/10.1098/rspb.2015.2053

Svensson GP, Hickman MO, Bartram S, Boland W, Pellmyr O, Raguso RA (2005) Chemistry and geographic variation of floral scent in Yucca filamentosa (Agavaceae). Am J Bot 92:1624-1631

Svensson GP, Pellmyr O, Raguso RA (2006) Strong conservation of floral scent composition in two allopatric yuccas. J Chem Ecol 32:2657-2665

Svensson GP, Pellmyr O, Raguso RA (2011) Pollinator attraction to volatiles from virgin and pollinated host flowers in a yucca/moth 
obligate mutualism. Oikos 120:1577-1583. https://doi.org/10.11 11/j.1600-0706.2011.19258.x

Thompson JN (2005) The geographic mosaic of coevolution. The University of Chicago Press, Chicago and London

Thompson JN (2010) The adaptive radiation of coevolving prodoxid moths and their host plants: greya moths and yucca moths. search of the causes of evolution: from field observations to mechanisms. Princeton University Press, Princeton

Thompson JN, Cunningham BM (2002) Geographic structure and dynamics of coevolutionary selection. Nature 417:735-738

Thompson JN, Schwind C, Friberg M (2017) Diversification of trait combinations in coevolving plant and insect lineages. Am Nat 190:171-184. https://doi.org/10.1086/692164

Thompson JN, Schwind C, Guimaraes PR Jr, Friberg M (2013) Diversification through multitrait evolution in a coevolving interaction. Proc Natl Acad Sci USA 110:11487-11492. https:// doi.org/10.1073/pnas.1307451110

Waelti MO, Muhlemann JK, Widmer A, Schiestl FP (2008) Floral odour and reproductive isolation in two species of Silene. J Evol Biol 21:111-121

Wallin EA, Kalinova B, Kindl J, Hedenstrom E, Valterova I (2020) Stereochemistry of two pheromonal components of the bumblebee wax moth. Aphomia Sociella Sci Rep 10:2094-2094. https://doi. org/10.1038/s41598-020-59069-1

Publisher's Note Springer Nature remains neutral with regard to jurisdictional claims in published maps and institutional affiliations. 